23

\title{
Мониторинг процесса иммерсионного оптического просветления коллагеновых волокон с помощью оптической когерентной томографии
}

\author{
(C) М.Е. Швачкина ${ }^{1}$, Д.Д. Яковлев ${ }^{1}$, Е.Н. Лазарева ${ }^{1,2}$, А.Б. Правдин ${ }^{1}$, Д.А. Яковлев ${ }^{1,}$ \\ ${ }^{1}$ Саратовский национальный исследовательский государственный университет имени Н.Г. Чернышевского, \\ 410012 Саратов, Россия \\ ${ }^{2}$ Национальный исследовательский Томский государственный университет, \\ 634050 Томск, Россия \\ I e-mail: yakovlevday@gmail.com
}

Поступила в редакцию 15.10 .2018 г.

В окончательной редакции 21.03.2019 г.

Принята к публикации 09.04.2019 г.

\begin{abstract}
Развитие метода иммерсионного оптического просветления биологических тканей - метода, широко используемого при исследовании морфологии тканей и их патологий in vitro и считающегося перспективным для применений in vivo в биофизических исследованиях и медицине, требует знания деталей взаимодействия иммерсионных жидкостей с биотканью, в частности характеристик процесса дегидратации ткани, обусловленного осмотическим действием иммерсионной жидкости, и процесса диффузии иммерсионного агента (ИА) в ткань. Оптические свойства дермы кожи, склеры глаза, сухожилия и многих других тканей определяются свойствами коллагеновых пучков, являющихся одним из главных компонентов этих тканей. В настоящей работе предложена удобная и надежная методика мониторинга оптических свойств и геометрии коллагеновых пучков при их иммерсионном просветлении in vitro, основанная на применении метода оптической когерентной томографии (ОКТ). Основным достоинством этой методики является то, что она позволяет одновременно отслеживать изменения геометрических и оптических характеристик ткани без прерывания естественного хода процесса иммерсионного просветления и получать надежные оценки характерных времен и скоростей как процесса дегидратации ткани, так и процесса диффузии ИА в ткань.
\end{abstract}

Ключевые слова: оптическая когерентная томография, биологические ткани, иммерсионное просветление.

DOI: $10.21883 /$ OS.2019.08.48052.302-18

\section{1. Введение}

Возможность увеличивать оптическую прозрачность биологических тканей с помощью иммерсионного просветления широко используется при исследовании структуры биотканей in vitro [1-6]. В настоящее время предпринимаются многочисленные попытки найти безопасные варианты использования иммерсионного просветления in vivo [1,5-9] для увеличения глубины проникновения излучения в оптической диагностике и фототерапии. Ключевыми процессами, определяющими механизм иммерсионного просветления, являются осмотическая дегидратация ткани под действием иммерсионного агента (ИА) и диффузия ИА в ткань. Надежная количественная информация о скорости и степени проявления этих процессов в конкретных условиях чрезвычайно важна при разработке технологий иммерсионного просветления. Это сделало актуальным поиск методов, в том числе оптических, позволяющих осуществлять такую характеризацию.

Сложность оптической характеризации процессов иммерсионного просветления отчасти обусловлена тем, что дегидратация ткани и диффузия ИА в ткань при близких к естественным уровням гидратации дают схо- жий оптический эффект, снижая рассеяние света в ткани. Поэтому составить достаточно полную картину протекания процессов дегидратации и диффузии ИА в ходе иммерсионного просветления, опираясь только на данные измерений оптических характеристик ткани, например ее коэффициента рассеяния или спектров отражения/пропускания [10,11], затруднительно, если вообе возможно. Значительно более ясное представление о протекании этих процессов можно получить, отслеживая одновременно как изменения оптических свойств, так и изменения геометрических параметров ткани [12], поскольку тенденции изменения объема ткани, определяемые осмотической дегидратацией и диффузией ИА, разнонаправлены: дегидратация приводит к уменьшению объема ткани, диффузия ИА в ткань - к увеличению. При применении фотометрических и спектрофотометрических методов, широко используемых для характеризации действия ИА на биоткани [10], одновременный мониторинг оптических и геометрических характеристик образцов ткани сопряжен с большими трудностями и, как правило, требует прерывания естественного хода процесса просветления и перепозиционирования образца $[12,13]$, что отрицательно сказывается на точности измерений. Для некоторых типов тканей такой мони- 
торинг может быть успешно осуществлен с помощью оптической когерентной томографии (ОКТ).

В настоящей работе мы представляем относительно простую ОКТ-методику, позволяющую исследовать кинетику взаимодействия ИА с коллагеновыми волокнами на образцах вторичных сухожильных пучков. Основным достоинством этой методики является то, что она позволяет непрерывно, без переустановок образца, производить мониторинг как геометрических параметров ткани, так и ее оптических параметров, в частности ее среднего группового показателя преломления, в ходе иммерсионного просветления. Поскольку средний показатель преломления ткани зависит от состава и объемного содержания тканевой жидкости, то по его измеренным (на различных стадиях просветления) значениям с учетом данных по изменению объема ткани можно оценить текущее содержание в ткани воды и ИА. Предлагаемая методика может быть также использована для оценки степени и скорости восстановления свойств ткани после процедуры иммерсионного просветления, при вымывании ИА, что важно в контексте возможных in vivo применений иммерсионного просветления.

\section{2. Методика измерений и обработка данных}

Суть предлагаемой нами методики измерений состоит в одновременном мониторинге с помощью ОКТ изменений объема исследуемого коллагенового пучка и его среднего группового показателя преломления в ходе иммерсионного просветления образца. В данном разделе мы представляем как саму методику, так и детали ее реализации и апробации в наших исследованиях.

В качестве образцов используются вторичные сухожильные пучки из хвоста крысы. Диаметр вторичных сухожильных пучков хвоста крысы обычно составляет от 200 до $500 \mu \mathrm{m}$. Для измерений по представляемой методике наиболее подходящими оказались пучки диаметром от 300 до $450 \mu \mathrm{m}$ (см. подраздел Образцы в конце данного раздела). В качестве ИА мы использовали водный раствор глицерина концентрацией 82.3 vol.\%, водный раствор пропиленгликоля концентрацией 89 vol.\%, водный раствор глюкозы с содержанием $40 \mathrm{wt} \%$, Омнипак-300 и полиэтиленгликоль ПЭГ-300.

При подготовке к ОКТ-измерениям исследуемый коллагеновый пучок, погруженный в физиологический раствор (0.9 wt.\% водный раствор хлорида натрия), слегка натягивается и закрепляется зажимами на предметном стекле (рис. 1,a). Затем он накрывается покровным стеклом и для получения скана поперечного сечения пучка в нативном состоянии устанавливается в ОКТсистему так, чтобы направление пучка было перпендикулярно направлению В-сканирования. Затем покровное стекло снимается, и быстро с помощью фильтровальной бумаги с поверхности предметного стекла удаляется физиологический раствор. После этого пучок окружается большим количеством ИА, снова накрывается покровным стеклом (количество агента, окружающего образец, должно быть достаточно большим, чтобы можно было пренебречь изменением среднего показателя преломления агента за счет выхода в него воды из образца) и устанавливается в ОКТ-систему в том же положении. С момента установки через определенные промежутки времени, сначала малые (порядка 20s), затем несколько большие (порядка минуты), фиксируются ОКТ-изображения, отображающие поперечное сечение исследуемого пучка и верхнюю границу предметного стекла. Примеры изменения ОКТ-изображений пучков в процессе иммерсионного просветления показаны на рис. $1, b$. Для измерений нами использовался томограф ThorLabs-OCP930SR (центральная длина волны зондирующего излучения $\lambda_{0}=930 \mathrm{~nm}$, ширина полосы $100 \mathrm{~nm}$ ).

Для оценки среднего показателя преломления ткани по данным ОКТ мы используем общий подход [14-17], предполагающий определение группового показателя преломления и геометрической толщины образца из измеренных значений оптической длины пути $l_{\mathrm{S}}=n_{\mathrm{A}} d$, где $d$ - геометрическая толщина образца для данной линии А-сканирования, а $n_{\mathrm{A}}-$ средний групповой показатель преломления образца для этой линии сканирования, и вертикального смещения $\Delta_{\mathrm{R}}$ изображения отражающей поверхности, расположенной за образцом, относительно его положения в отсутствие образца (в приложении к рассматриваемой геометрии данный подход наглядно представлен в [18]). В нашей геометрии эксперимента, как и в $[17,18]$, функцию такой отражающей поверхноси выполняет фронтальная поверхность стеклянной подложки. Как видно из томограмм, приведенных на рис. $1, b$, изображение верхней границы подложки под образцом смещается со временем, свидетельствуя об изменении $l_{\mathrm{S}}$. В случаях, когда показатель преломления окружающей образец среды мог считаться однородным, средний групповой показатель преломления ткани для рассматриваемой линии А-сканирования рассчитывался по найденным по ОКТ-скану значениям $l_{\mathrm{S}}$ и $\Delta_{\mathrm{R}}$ по формуле

$$
n_{\mathrm{A}}=\frac{n_{0} l_{\mathrm{S}}}{l_{\mathrm{S}}-\Delta_{\mathrm{R}}}
$$

где $n_{0}$ - групповой показатель преломления среды, окружающей образец (физраствор или иммерсионная жидкость) [18]. Средний групповой показатель преломления образца, $n_{\mathrm{t}}$, рассчитывался посредством усреднения значений $n_{\mathrm{A}}$, полученных для $3-5$ линий А-сканирования. По нашим оценкам при высоте поперечного сечения образца больше $300 \mu \mathrm{m}$ описанный способ может обеспечить точность определения $n_{\mathrm{t}}$ порядка 0.003-0.005. Групповые показатели преломления ИА и воды рассчитывались нами по спектральным зависимостям фазового показателя преломления среды в 


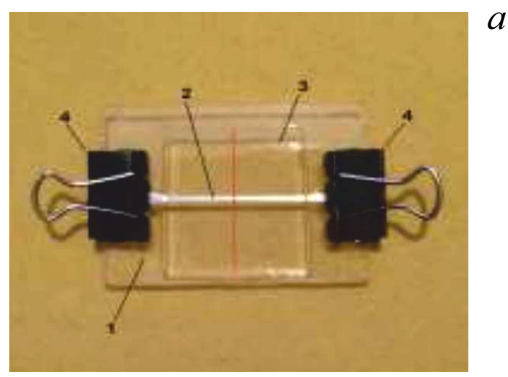

$a$

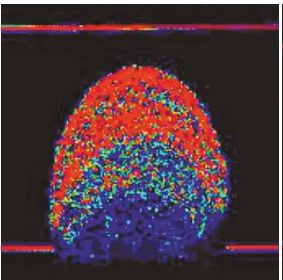

Initial state

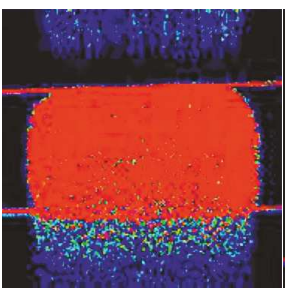

Initial state



$0.87 \mathrm{~min}$

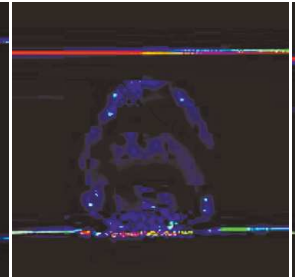

$9.2 \mathrm{~min}$

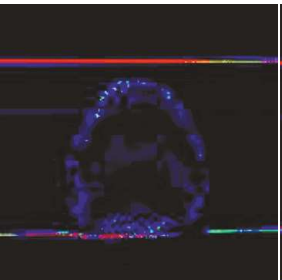

$25.5 \mathrm{~min}$

Clearing in Omnipaque

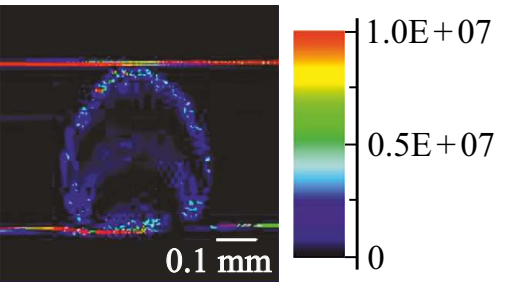

$78 \mathrm{~min}$

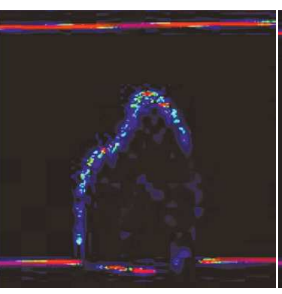

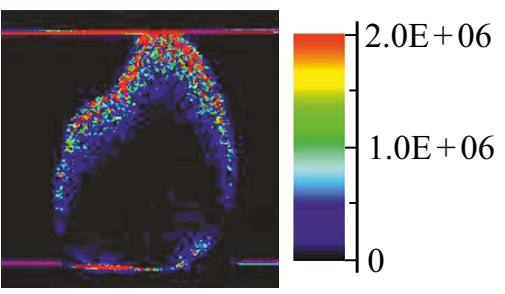

$25.2 \mathrm{~h}$

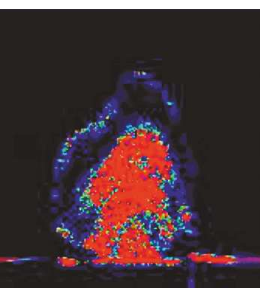

$0.6 \mathrm{~min}$
$11 \mathrm{~min}$
Clearing in glycerol solution

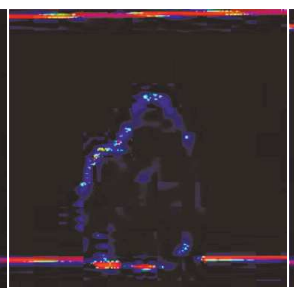

Pис. 1. (a) Крепление образца на предметном стекле. 1 - предметное стекло, 2 - образец, 3 - покровное стекло, 4 - зажимы. Красной пунктирной линией показано расположение плоскости сканирования. (b) Серии ОКТ-сканов образцов сухожильных пучков, просветлявшихся в Омнипак-300 и в $82.3 \%$ растворе глицерина. Показаны сканы образцов в исходном состоянии (в физрастворе) и после их погружения в ИА в разные моменты времени с момента погружения. Масштаб на всех сканах одинаков.

соответствии с общей формулой $[19,20]$

$$
n_{\mathrm{g}}\left(\lambda_{0}\right)=n_{\mathrm{p}}\left(\lambda_{0}\right)-\left.\lambda_{0} \frac{d n_{\mathrm{p}}}{d \lambda}\right|_{\lambda=\lambda_{0}},
$$

где $n_{\mathrm{p}}$ и $n_{\mathrm{g}}-$ соответственно фазовый и групповой показатели преломления среды, а $\lambda_{0}$ — центральная длина волны зондирующего излучения в вакууме (в нашем случае $\lambda_{0}=930 \mathrm{~nm}$ ). Фазовые показатели преломления ИА были измерены с помощью многоволнового рефрактометра Аббе DR-M2/1550 (Atago, Япония): источником излучения служила лампа накаливания высокой мощности; для спектральной селекции использовались узкополосные интерференционные фильтры с максимумом пропускания на длинах волн 480, 486, 546, 589, 644, 656, 680, 930, 1100, 1300 и $1500 \mathrm{~nm}$. Полученные данные по фазовым показателям ИА представлены на рис. 2. Рассчитанные по ним значения групповых показателей преломления ИА представлены в табл. 1 (приведены значения погрешности на $90 \%$ уровне значимости, оцененные исходя из точности определения производной фазового показателя преломления по длине волны).
Таблица 1. Групповой показатель преломления рассматриваемых ИА для $\lambda_{0}=930 \mathrm{~nm}$

\begin{tabular}{l|c}
\hline \multicolumn{1}{c|}{ Вещество } & $n_{\mathrm{g}}, \pm 0.0015$ \\
\hline ПЭГ-300 & 1.4612 \\
82.3 vol. \% раствор глицерина & 1.4592 \\
Омнипак-300 & 1.4504 \\
89 vol.\% раствор пропиленгликоля & 1.4299 \\
40 wt. \% раствор глюкозы & 1.3990
\end{tabular}

Групповой показатель преломления физиологического раствора при обработке данных предполагался приближенно равным групповому показателю преломления воды. Для расчета группового показателя преломления воды мы использовали данные работы [21] по спектральной зависимости фазового показателя преломления, давшие значение $n_{\mathrm{g}}=1.3416$ для $\lambda_{0}=930 \mathrm{~nm}$.

Предположение об однородности показателя преломления среды, окружающей образец, полностью оправдано при измерении показателя преломления образ- 


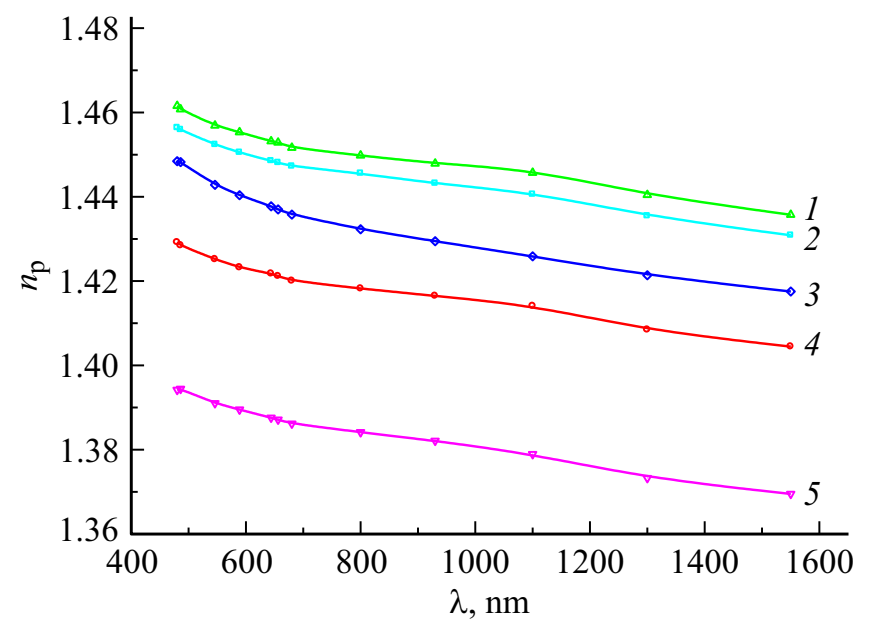

Рис. 2. Зависимость фазового показателя преломления $n_{\mathrm{p}}$ используемых ИА от длины волны $\lambda: 1-$ ПЭГ-300, $2-$ $82.3 \%$ раствор глицерина, 3 - Омнипак-300, $4-89 \%$ раствор пропиленгликоля, $5-40 \%$ раствор глюкозы. Погрешность измерений составляет порядка 0.0003 (SEM).

ца в исходном состоянии, когда образец находится в физрастворе. При иммерсионном просветлении, которое на начальном этапе сопровождается быстрой дегидратацией ткани, неоднородность показателя преломления окружающей среды имеет место из-за диффузии воды, выходящей из образца, в объеме ИА. На этапах, когда вода, вышедшая из образца, оказывается достаточно равномерно распределенной по объему жидкости, окружающей образец, предположение о приближенной однородности показателя преломления этой жидкости также является оправданным. При этом исходя из того, что объем ИА многократно превышает объем вышедшей в него воды, можно считать показатель преломления окружающей среды приблизительно равным исходному показателю преломления ИА. На стадии быстрой дегидратации, в течение 5-10 min после погружения образца в иммерсионную жидкость, концентрация воды в иммерсионной жидкости вблизи образца оказывается значительно выше, чем на некотором удалении от него, и соответственно показатель преломления окружающей среды вблизи образца оказывается существенно ниже, чем вдали от него.

Указанием на существование большого градиента показателя преломления в окрестности образца является искривление изображения поверхности подложки вне области геометрической проекции образца на ОКТ-сканах. В качестве примера на рис. 3, a приведен ОКТ-скан для сухожильного пучка (образец Р1), просветляемого в растворе пропиленгликоля, через $1.3 \mathrm{~min}$ после его погружения в иммерсионную жидкость. Зоны искривления изображения границы предметного стекла, обусловленные неоднородностью показателя преломления жидкости, окружающей образец, указаны стрелками. По величине смещения изображения верхней границы
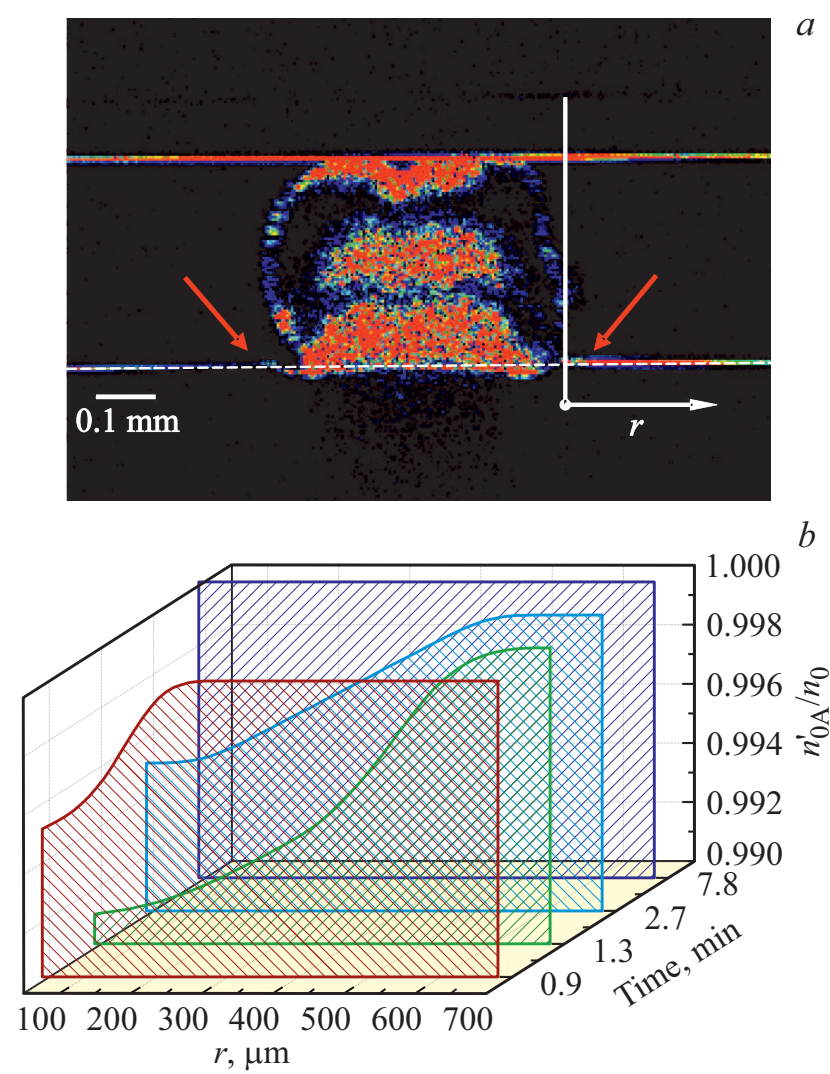

Рис. 3. (а) ОКТ-скан сухожильного пучка (образец Р1), полученный через $1.3 \mathrm{~min}$ после его погружения в раствор пропиленгликоля, $(b)$ зависимость отношения среднего группового показателя преломления жидкости вблизи образца к исходному показателю преломления ИА от расстояния от линии А-сканирования до образца.

предметного стекла можно количественно оценить отношение среднего группового показателя преломления жидкости вблизи образца для данного А-скана $\left(n_{0 \mathrm{~A}}^{\prime}\right)$ к исходному показателю преломления ИА $\left(n_{0}\right)$ по формуле

$$
\frac{n_{0 \mathrm{~A}}^{\prime}}{n_{0}}=\left(1+\frac{\Delta_{\mathrm{A}}}{l_{\mathrm{A}}}\right)^{-1},
$$

где $l_{\mathrm{A}}$ - оптическая длина пути света через иммерсионную жидкость в отсутствие градиента показателя преломления для данного А-скана и $\Delta_{\mathrm{A}}-$ величина смещения изображения верхней границы предметного стекла, обусловленного изменением показателя преломления окружающей среды. На рис. $3, b$ в качестве примера показано, как изменялось отношение $n_{0 \mathrm{~A}}^{\prime} / n_{0}$ как функция расстояния $r$ от линии А-скана до образца со временем с момента погружения образца Р1 в раствор пропиленгликоля. Из этого рисунка видно, что в течение первых полутора-двух минут градиент показателя преломления увеличивался и достиг максимума. Затем он начал уменьшаться и через 7-8 min с момента погружения образца в иммерсионную жидкость, вскоре после окончания стадии быстрой дегидратации, практически исчез. 
Отмеченные пространственные вариации показателя преломления окружающей образец среды в определенных ситуациях должны учитываться при определении среднего показателя преломления ткани на стадии быстрой дегидратации. Негативное влияние неоднородности среды, окружающей образец, на точность определения показателя преломления становится существенным, когда над и/или под образцом находится значительная толща ИА. В таких случаях значительное улучшение точности оценок достигается использованием для расчета показателя преломления $n_{\mathrm{A}}$ вместо формулы (1) следующей формулы, частично учитывающей неоднородность среды вокруг образца:

$$
n_{\mathrm{A}}=\frac{n_{0} l_{\mathrm{S}}}{l_{\mathrm{S}}-\Delta_{\mathrm{R}}}\left[1+\frac{L_{1}+L_{2}}{L_{\mathrm{S}}}\left(1-\frac{n_{0 \mathrm{~A}}^{\prime}}{n_{0}}\right)\right]^{-1},
$$

где $L_{\mathrm{S}}$ - толщина образца на данной линии сканирования, $L_{1}$ и $L_{2}$ - значения толщины слоя жидкости над и под образцом на этой линии, $n_{0 \mathrm{~A}}^{\prime}-$ значение среднего показателя преломления окружающей среды для некоторой линии А-сканирования в непосредственной близости от образца, рассчитанное по формуле (2). Величина отношения $\left(L_{1}+L_{2}\right) / L_{\mathrm{S}}$ с достаточной для данной коррекции точностью может быть рассчитана по рассматриваемому ОКТ-скану. Мы использовали эту коррекцию при обработке данных в случаях просветления в ПЭГ и растворе глицерина.

Площадь поперечного сечения исследуемого коллагенового пучка, $S$, рассчитывалась по площади его изображения на ОКТ-скане как

$$
S=\frac{S_{\text {OCT-pix }} k_{\mathrm{pm}}}{n_{\mathrm{t}}}
$$

где $S_{\text {OST-pix }}$ - площадь изображения сечения пучка на ОКТ-скане в пикселях, $k_{\mathrm{pm}}$ - площадь области, приходящейся на один пиксель изображения, в квадратных миллиметрах, при показателе преломления отображаемой среды, равном 1 (инструментальный параметр; в нашем случае $\left.k_{\mathrm{pm}}=1.2632 \cdot 10^{-5} \mathrm{~mm}^{2} / \mathrm{pix}\right)$, и $n_{\mathrm{t}}-$ средний групповой показатель преломления исследуемого пучка, рассчитанный по этому же скану. Для определения площади поперечного сечения пучка на ОКТ-изображении нами использовалась свободно распространяемая компьютерная программа Ісу [22].

Одним из параметров, отслеживаемых в эксперименте, является коэффициент изменения объема пучка, определяемый как $k_{\mathrm{s}}=V / V_{0}$, где $V$ и $V_{0}$ - значения объема пучка в заданный момент времени и в исходном состоянии соответственно. Напомним, что в нашем случае концы исследуемого сухожильного пучка зафиксированы, и последний изначально находится в слегка натянутом состоянии. Как показали эксперименты с использованием различных ИА, закрепленный таким образом коллагеновый пучок, как правило, остается в натянутом состоянии на всех стадиях взаимодействия с ИА в течение нескольких дней. Поэтому для количественного контроля изменения объема образца ткани при обезвоживании и набухании в данной геометрии эксперимента достаточно следить за изменением площади сечения пучка. Поскольку его длина не изменяется, $k_{\mathrm{s}}$ может рассчитываться через соответствующие площади сечения пучка как $k_{\mathrm{s}}=S / S_{0}$, что и используется в предлагаемой методике.

Объемное содержание воды в ткани $c_{\mathrm{w}}$ в момент измерения исходной площади сечения образца (оно варьировалось от образца к образцу в пределах от 0.644 до 0.706$)$ оценивалось по значению среднего группового показателя преломления образца с использованием формулы

$$
n_{\mathrm{t}}=\left(1-c_{\mathrm{w}}\right) n_{\mathrm{dry}}+n_{\mathrm{w}} c_{\mathrm{w}}
$$

с $n_{\mathrm{w}}=1.3416$ и $n_{\mathrm{dry}}=1.594$ [18], т.е. рассчитывалось как $c_{\mathrm{w}}=\left(n_{\text {dry }}-n_{\mathrm{t}}\right) /\left(n_{\mathrm{dry}}-n_{\mathrm{w}}\right) . \mathrm{B}$ работе [18] было показано, что функция (3) с указанными значениями коэффициентов хорошо аппроксимирует экспериментальные данные, полученные при воздушном высушивании аналогичных образцов и их последующей регидратации в физиологическом растворе в области значений $0.45<c_{\mathrm{w}}<1$. Среднее значение объемного содержания воды для нативных образцов оценено как $0.677 \pm 0.003[18]$.

Учитывая вариацию содержания воды в образцах в начальном состоянии, для характеризации изменения объема ткани наряду с параметром $k_{\mathrm{s}}$ мы использовали параметр

$$
k_{\mathrm{ss}}=\frac{V}{V_{0 \mathrm{~S}}}
$$

где $V_{0 \mathrm{~S}}$ - объем, который бы имел образец в исходном состоянии, если бы объемное содержание воды в нем равнялось 0.677 (среднее значение $c_{\mathrm{w}}$ для нативных образцов; обозначим его $\left.c_{\mathrm{w} 0 \mathrm{~S}}\right)$. Этот параметр, который мы условно назвали стандартным коэффициентом изменения объема, рассчитывался по значениям $k_{\mathrm{s}}$ для данного образца по формуле

$$
k_{\mathrm{ss}}=k_{\mathrm{s}} \frac{1-c_{\mathrm{w} 0 \mathrm{~S}}}{1-c_{\mathrm{w} 0}},
$$

где $c_{\text {w0 }}-$ начальное объемное содержание воды в данном образце, или по формуле

$$
k_{\mathrm{ss}}=k_{\mathrm{s}} \frac{n_{\mathrm{t} 0 \mathrm{~S}}-n_{\mathrm{w}}}{n_{\mathrm{t} 0}-n_{\mathrm{w}}},
$$

где $n_{\mathrm{t} 0 \mathrm{~S}}-$ значение $n_{\mathrm{t}}$, которое дает формула (3) при $c_{\mathrm{w}}=0.677, n_{\mathrm{t} 0}-$ значение $n_{\mathrm{t}}$ для данного образца в исходном состоянии. Формула (5) получается подстановкой (3) в (4). Удобство параметра $k_{\mathrm{ss}}$ отчасти связано с тем, что точки состояния на плоскости $\left(k_{\mathrm{ss}}, n_{\mathrm{t}}\right)$ для разных образцов, дегидратируемых одинаковым образом, приблизительно ложатся на одну линию независимо от величины $c_{\mathrm{w} 0}$.

Образцы. Образцы вторичных сухожильных пучков были получены из хвостов зрелых лабораторных крыс 




Рис. 4. Типичные временные зависимости коэффициента изменения объема вторичных сухожильных пучков $k_{\mathrm{s}}$ при их просветлении в различных ИА: $1-$ ПЭГ-300, $2-82.3 \%$ раствор глицерина, 3 - Омнипак-300, 4 - 89\% раствор пропиленгликоля, $5-40 \%$ раствор глюкозы.

(исследование одобрено Комитетом по этике ФГБОУ ВО „Саратовский государственный медицинский университет им. В.И. Разумовского“ Минздрава России). До момента измерений образцы хранились в физиологическом растворе не более 7 дней. Никаких статистически значимых изменений площади сечения пучков и их оптических характеристик, а именно средних групповых показателей преломления и двулучепреломления, в течение 7 дней хранения обнаружено не было.

Для измерений нами использовались пучки диаметром от 300 до $450 \mu \mathrm{m}$. Относительно небольшой диаметр пучка позволял получать четкое ОКТ-изображение верхней границы предметного стекла под образцом, даже когда образец находится в нативном состоянии, и его положение могло быть определено с высокой точностью. Это обеспечивало хорошую точность измерений как среднего группового показателя преломления ткани, так и площади сечения пучка. При большем диаметре пучка изображения верхней границы предметного стекла под образцом не было видно, или оно было сильно размытым. При меньшем диаметре пучков значения $\Delta_{R}$ и $l_{\mathrm{S}}$ были слишком маленькими для достаточно точного определения показателя преломления $n_{\mathrm{t}}$.

\section{Результаты и обсуждение}

На рис. 4-6 показаны типичные кинетические кривые для коэффициентов изменения объема $k_{\mathrm{s}}$ и $k_{\mathrm{ss}}$ и среднего группового показателя преломления ткани $n_{\mathrm{t}}$ для $\lambda_{0}=930 \mathrm{~nm}$ при просветлении образцов в пяти рассматриваемых иммерсионных жидкостях (планки погрешностей показывают доверительный интервал на $90 \%$ уровне значимости). Значения параметров, соответствующие начальному состоянию, были получены

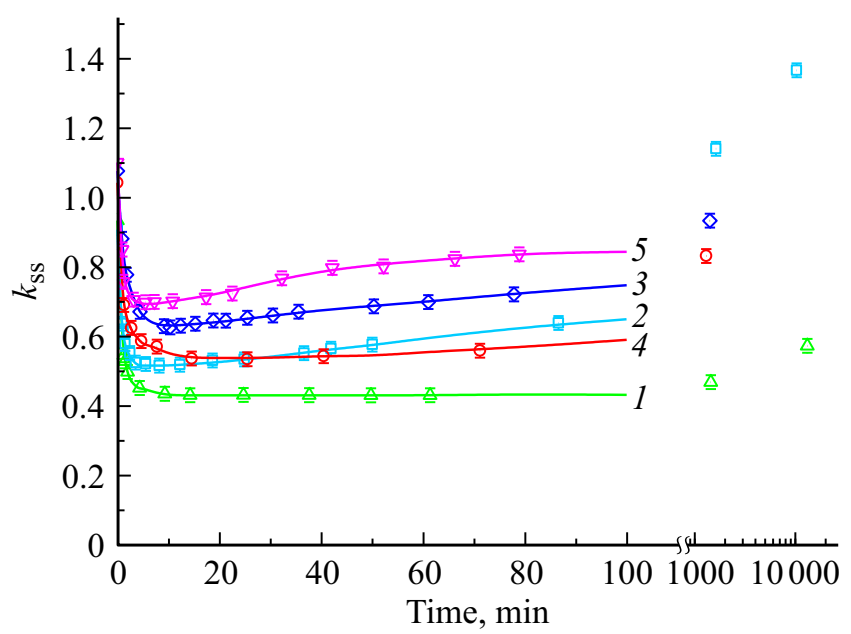

Рис. 5. Типичные временные зависимости стандартного коэффициента изменения объема вторичных сухожильных пучков $k_{\mathrm{ss}}$ при их просветлении в различных ИА: $1-$ ПЭГ-300, $2-82.3 \%$ раствор глицерина, $3-$ Омнипак-300, $4-89 \%$ раствор пропиленгликоля, $5-40 \%$ раствор глюкозы.

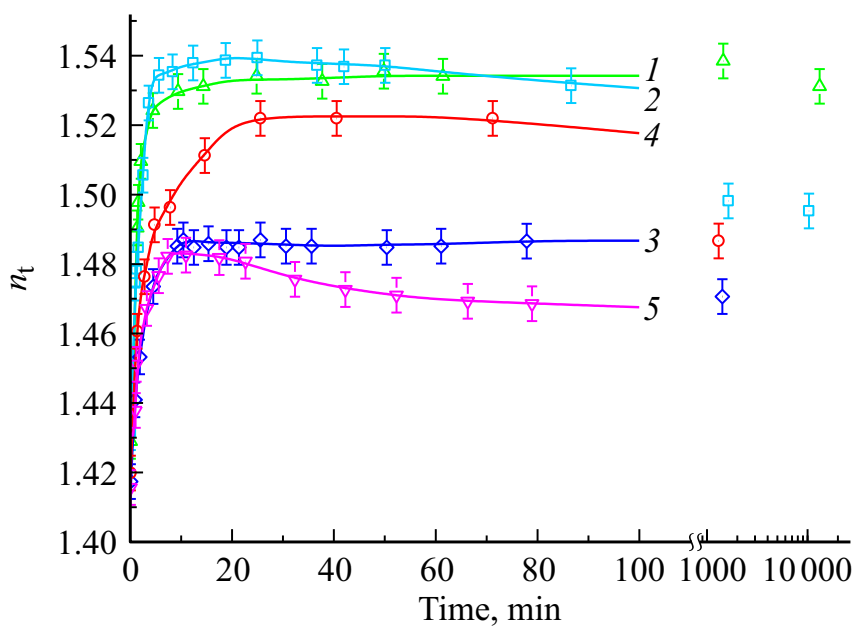

Рис. 6. Изменение среднего группового показателя преломления сухожильных пучков $n_{\mathrm{t}}$ при их оптическом просветлении в различных ИА: $1-$ ПЭГ-300, $2-82.3 \%$ раствор глицерина, 3 - Омнипак-300, 4 - 89\% раствор пропиленгликоля, 5 $40 \%$ раствор глюкозы.

при измерении параметров образца, находящегося в физиологическом растворе, непосредственно перед процедурой иммерсионного просветления.

В общем случае можно условно разделить процесс взаимодействия ткани с иммерсионной жидкостью на две основные стадии. Первая стадия, начальная это стадия дегидратации, на которой доминирующую роль играет обезвоживание ткани за счет осмотического действия ИА. На этой стадии происходит уменьшение объема ткани за счет выхода из нее воды. Вторая стадия - это стадия набухания ткани. Доминирующую роль на этой стадии играет диффузия ИА в ткань. Исходя из этого можно считать моментом окончания 
Таблица 2. Изменение параметров трех образцов коллагеновых пучков при их иммерсионном просветлении в $82.3 \%$ растворе глицерина

\begin{tabular}{c|c|c|c|c|c|c|c|c|c}
\hline \multirow{2}{*}{ № } & \multirow{2}{*}{$d_{0}, \mathrm{~mm}$} & \multirow{2}{*}{$n_{\mathrm{t} 0}, \pm 0.004$} & \multirow{2}{*}{$t_{\mathrm{DH}}, \min$} & \multicolumn{4}{|c|}{$k_{\mathrm{ss}}, \pm 0.02$} & \multicolumn{2}{c}{$n_{\mathrm{t}}, \pm 0.004$} \\
\cline { 4 - 9 } & & & & $t_{\mathrm{DH}}$ & $20 \min$ & 100 min & 1 day & $t_{\mathrm{DH}}$ & 1 day \\
\hline 1 & 0.376 & 1.431 & $8.2 \pm 3.5$ & 0.515 & 0.526 & 0.648 & 1.139 & 1.535 & 1.498 \\
2 & 0.364 & 1.420 & $10.7 \pm 3.1$ & 0.510 & 0.522 & 0.600 & 1.098 & 1.537 & 1.502 \\
3 & 0.314 & 1.414 & $9.5 \pm 3.6$ & 0.522 & 0.540 & 0.675 & 1.211 & 1.533 & 1.498
\end{tabular}

первой стадии момент времени $\left(t_{\mathrm{DH}}\right)$, в который ткань приобретает наименьший объем. В этот момент времени коэффициенты $k_{\mathrm{s}}$ и $k_{\mathrm{ss}}$ имеют свое наименьшее значение, что позволяет легко определить $t_{\mathrm{DH}}$ по измеренным временным зависимостям $k_{\mathrm{s}}$ и $k_{\mathrm{ss}}$. В рассматриваемых примерах $t_{\mathrm{DH}}$ составило $8.2 \mathrm{~min}$ для раствора глицерина, $14.6 \mathrm{~min}$ для раствора пропиленгликоля, $5.5 \mathrm{~min}$ для раствора глюкозы и $10.4 \mathrm{~min}$ для Омнипак. В случае ПЭГ $t_{\mathrm{DH}}$ составило около $9 \mathrm{~min}$, при этом объем ткани практически не изменялся на протяжении последующих 50-60 min. Это легко объяснимо. ПЭГ имеет длинные молекулы, не способные быстро диффундировать в ткань, поэтому при относительно коротком контакте с тканью, например в течение часа, действие ПЭГ на ткань состоит лишь в ее обезвоживании, что часто используется в биофизических исследованиях. При длительном выдерживании в ПЭГ, как видно из представленных данных, некоторое набухание ткани все же происходит. По полученным кривым для $k_{\mathrm{s}}$ и $k_{\mathrm{ss}}$ можно оценить скорость диффузии ИА в ткань на стадии набухания и для других ИА. Данные в табл. 2 для трех образцов, просветлявшихся в $82.3 \%$ растворе глицерина, позволяют оценить степень разброса результатов, полученных для разных образцов в одном и том же ИА. Средний диаметр образца в исходном состоянии, $d_{0}$, значения которого указаны в таблице, рассчитывался по формуле $d_{0}=2 \sqrt{S_{0} / \pi}$. Можно заметить, что несмотря на существенную разницу в начальном содержании воды в образцах, о чем можно судить по начальным значениям $n_{t}$, значения $t_{\mathrm{DH}}$ и значения $k_{\mathrm{ss}}(t)$ и $n_{\mathrm{t}}(t)$ при $t \geq t_{\mathrm{DH}}$ оказались близкими для разных образцов. То же наблюдалось и для других ИА.

Из сопоставления рис. 4 и 6 видно, что на стадии дегидратации средний показатель преломления ткани резко увеличивается - в ткани понижается содержание компонента с наименьшим показателем преломления (воды). Можно обратить внимание, что для всех пяти рассматриваемых ИА в момент достижения наименьшего объема средний показатель преломления ткани $n_{\mathrm{t}}$ оказался выше, чем показатель преломления ИА $n_{0}$. Поэтому, если на следующей стадии выхода воды из ткани не происходит, диффузия ИА в ткань должна приводить к понижению $n_{\mathrm{t}}$. Если же вода из ткани на этой стадии продолжает выходить, может оказаться существенной тенденция к повышению $n_{\mathrm{t}}$ за счет за- мещения воды в ткани ИА. Как видно из сравнения рис. 4 и 6, эта тенденция играет определяющую роль при просветлении в Омнипак - в течение по меньшей мере часа набухания в этом ИА показатель преломления образца $n_{\mathrm{t}}$ не уменьшался, тогда как объем ткани за это время заметно увеличился. При просветлении в растворе глицерина, растворе пропиленгликоля и растворе глюкозы увеличение объема образца на стадии набухания сопровождалось уменьшением $n_{\mathrm{t}}$. В этих случаях, по всей видимости, выхода воды из ткани на стадии набухания не происходит совсем, или он является столь малым, что тенденция к понижению показателя преломления ткани за счет диффузии ИА в ткань преобладает над тенденцией к его повышению за счет выхода воды.

Рисунок 7 дает представление о характере и степени неоднородности показателя преломления образцов на разных стадиях иммерсионного просветления. Представленные данные получены для образца P1, просветляемого в растворе пропиленгликоля. Можно видеть, что в течение первых $5 \mathrm{~min}$ после погружения образца в иммерсионную жидкость значение показателя преломления минимально в центре сухожильного пучка и увеличивается к границам образца, что свидетельствует о большей степени дегидратации ткани вблизи границ. К концу стадии дегидратации неоднородность показателя преломления внутри образца почти исчезает. На стадии набухания долгое время значения показателя преломления ткани вблизи границ оказываются меньше их значений в центре пучка, что отражает картину диффузии ИА в ткань.

Степень проявления диффузии ИА на этапе дегидратации может быть оценена посредством сравнения траектории движения точки состояния образца (кривой эволюции) в пространстве $\left(k_{\mathrm{ss}}, n_{\mathrm{t}}\right)$ в заданных условиях просветления с кривыми эволюции, соответствующими чистой дегидратации или регидратации аналогичных образцов (рис. 8). Данные для последних были получены нами в экспериментах по воздушной дегидратации образцов c последующей регидратацией в физрастворе (метод измерения и соответствующие результаты были детально представлены нами в [18]), а также дегидратации в ПЭГ. На рис. 8 заштрихован коридор значений $\left(k_{\mathrm{ss}}, n_{\mathrm{t}}\right)$, которые были получены при воздушном высушивании и регидратации образцов. Точки состояния, полученные 

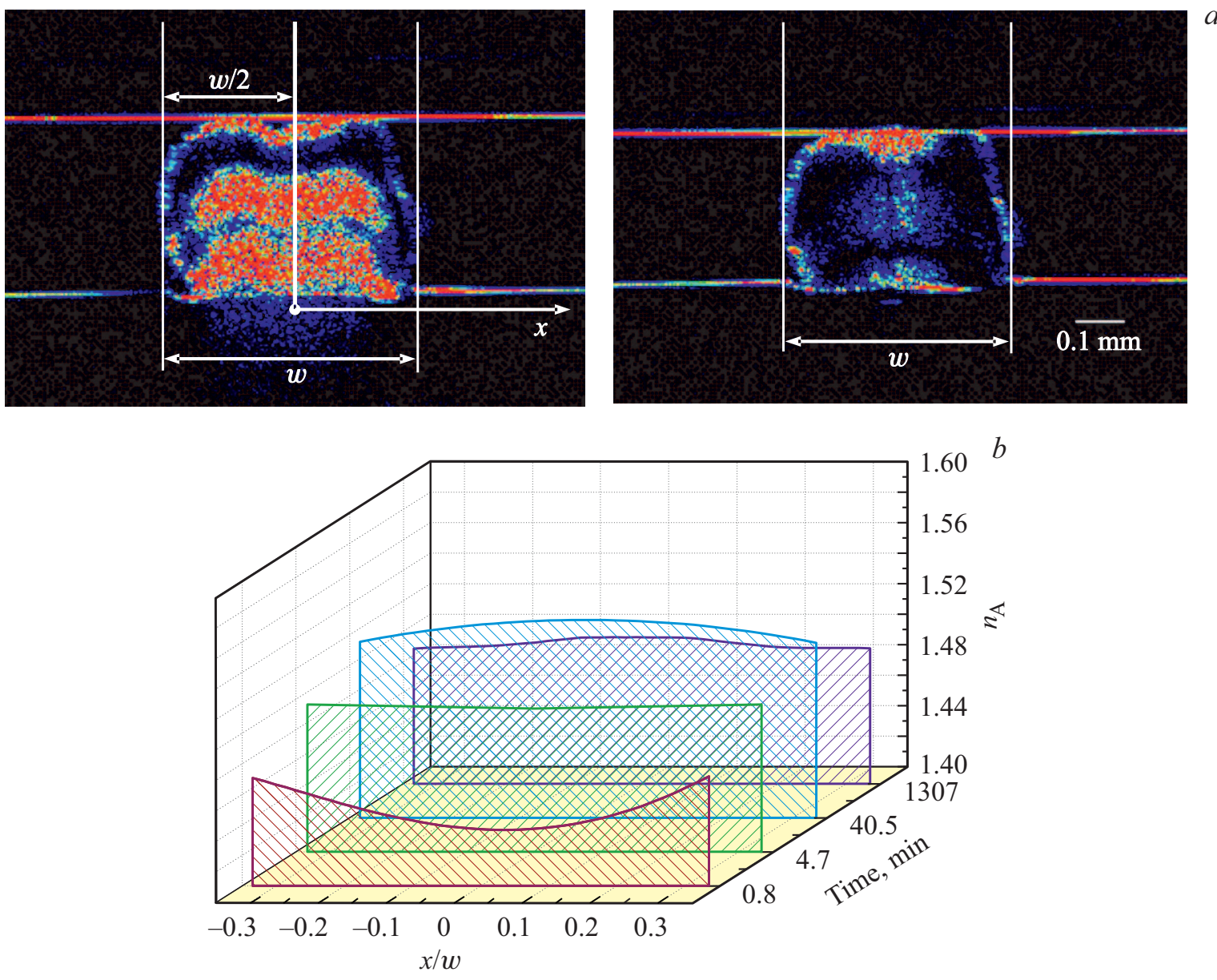

Рис. 7. (a) ОКТ-сканы образца Р1, просветляемого в растворе пропиленгликоля, и используемая система координат $(w-$ ширина коллагенового пучка). (b) Пространственные зависимости показателя преломления $n_{\mathrm{A}}$ образца в разные моменты времени после его погружения в иммерсионную жидкость.

Таблица 3. Объемное содержание воды и ИА в сухожильных пучках в момент достижения минимального объема

\begin{tabular}{l|c|c|c}
\hline \multicolumn{1}{c|}{ ИА } & $t_{\mathrm{DH}}, \min$ & Объемное содержание воды & Объемное содержание ИА \\
\hline 82.3 vol.\% раствор глицерина & $8.2 \pm 3.5$ & $0.070 \pm 0.006$ & $0.304 \pm 0.046$ \\
Омнипак-300 & $10.4 \pm 3.0$ & $0.345 \pm 0.023$ & $0.139 \pm 0.039$ \\
89 vol.\% раствор пропиленгликоля & $14.6 \pm 2.5$ & $0.197 \pm 0.003$ & $0.201 \pm 0.063$ \\
40 wt.\% раствор глюкозы & $5.5 \pm 2$ & $0.219 \pm 0.004$ & $0.318 \pm 0.067$
\end{tabular}

при дегидратации образцов в ПЭГ показаны незакрашенными треугольниками $(\triangle)$. Штрихпунктирная линия на рис. 8, практически проходящая через эти точки (отклонение не превышает ошибки измерений), соответствует линейной зависимости показателя преломления ткани от объемного содержания воды, выражаемой формулой (3). В области малых значений $k_{\mathrm{ss}}$ точки $\left(k_{\mathrm{ss}}, n_{\mathrm{t}}\right)$, полученные при воздушном высушивании образцов, лежат в большинстве своем ниже кривой, соответствующей (3). Есть основания полагать [23], что основной причиной более низкого тренда при воздушном высушивании является образование в ткани воздушных пор. При дегидратации в ПЭГ таких пор не возникает, как и при дегидратации в других ИА. Поэтому мы склонны рассматривать данные для дегидратации в ПЭГ как более подходящие для построения эталонной кривой чистой дегидратации для рассматриваемой задачи, чем данные для воздушного высушивания, а штрихпунктирную кривую на рис. 8, соответствующую (3), - как хороший вариант такой эталонной кривой. Для образцов, подвергнутых иммерсионному просветлению, незакрашенные символы на рис. 8 показывают экспериментальные точки, полученные в течение 60-85 min нахождения образца в ИА, а закрашенные символы представляют данные, полученные более чем через $21 \mathrm{~h}$ после погружения образца в ИА. Экспериментальные точки, соответствующие начальным 


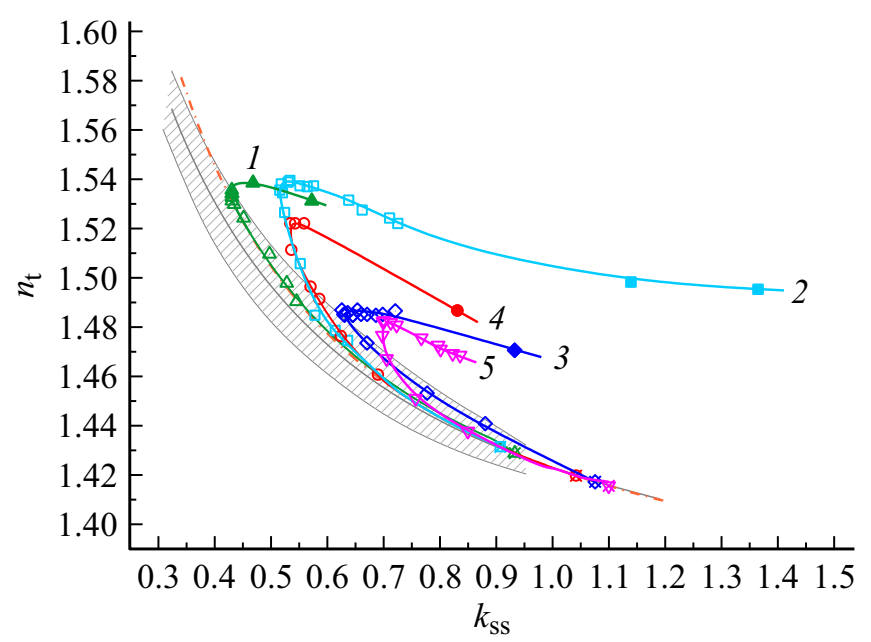

Рис. 8. Траектории движения точек состояния $\left(k_{\mathrm{ss}}, n_{\mathrm{t}}\right)$ при иммерсионном просветлении коллагеновых пучков в различных ИА: $1-$ ПЭГ-300, $2-82.3 \%$ раствор глицерина, $3-$ Омнипак-300, $4-89 \%$ раствор пропиленгликоля, $5-40 \%$ раствор глюкозы.

состояниям, отмечены крестиками. Из рис. 8 видно, что на начальной стадии просветления кривые эволюции всех просветляемых образцов идут вблизи эталонной кривой дегидратации-регидратации в пределах коридора значений, полученных при дегидратации, воздушной и в ПЭГ. Затем эти кривые выходят за пределы указанного коридора в область больших значений $n_{\mathrm{t}}$, что является очевидным признаком диффузии ИА в ткань: показатели преломления ИА выше показателя преломления воды, поэтому замена в ткани некоторого количества воды на ИА при сохранении объема ткани должна приводить к увеличению ее среднего показателя преломления. Можно заметить, что в случаях просветления в растворах пропиленгликоля, глицерина и глюкозы точки состояния, соответствующие моментам времени, в которые объем ткани является наименьшим, лежат значительно выше эталонной кривой дегидрации-регидрации, что свидетельствует о том, что к окончанию стадии дегидратации в ткани уже находится значительное количество ИА. Используя закон Гладстона-Даля [24], мы оценили по экспериментальным значениям $k_{\mathrm{s}}$ и $n_{\mathrm{t}}$ содержание воды и ИА в ткани в момент достижения ею минимального объема. Полученные данные представлены в табл. 3 . Использованный нами способ оценки содержания воды и ИА по данным для $k_{\mathrm{s}}$ и $n_{\mathrm{t}}$ требует отдельного рассмотрения; он будет представлен в последующих публикациях.

\section{Заключение}

В работе предложена относительно простая ОКТметодика для изучения особенностей воздействия ИА на коллагеносодержащие биологические ткани, позволяющая оценивать скорость и степень дегидратации ткани под действием ИА, а также скорость диффузии ИА в ткань. Приведены экспериментальные примеры, демонстрирующие возможности этой методики.

\section{Финансирование работы}

Работа выполнена при продержке РФФИ в рамках проектов № 17-00-00275 (17-00-00272), 17-00-00270/17 и 18-52-16025/18 и Минобрнауки РФ в рамках проекта № 3.1586.2017/4.6.

\section{Конфликт интересов}

Авторы заявляют, что у них нет конфликта интересов.

\section{Список литературы}

[1] Тучин В.В. Оптика биологических тканей. Методы рассеяния света в медицинской диагностике. М.: Физматлит, 2012. $812 \mathrm{c}$.

[2] Azaripour A., Lagerweij T., Scharfbillig C., Jadczak A.E., Willershausen B., Van Noorden C.J. // Progress in Histochemistry and Cytochemistry. 2016. V. 51. N 2. P. 9. doi 10.1016/j.proghi.2016.04.001

[3] Yakovlev D.D., Shvachkina M.E., Sherman M.M., Spivak A.V., Pravdin A.B., Yakovlev D.A. // J. Biomed. Opt. 2016. V. 21. N 7. P. 071111. doi 10.1117/1.JBO.21.7.071111

[4] Costantini I., Ghobril J.P., Di Giovanna A.P. et al. // Sci. Rep. 2015. V. 5. P. 9808 . doi $10.1038 /$ srep09808

[5] Zhu Dan, Larin K.V., Luo Q., Tuchin V.V. // Laser \& Photonics Rev. 2013. V. 7. N 5. P. 732. doi 10.1002/lpor.201200056

[6] Genina E.A., Bashkatov A.N., Tuchin V.V. // Expert Review of Medical Devices. 2010. V. 7. N 6. P. 825. doi 10.1586/erd.10.50

[7] Генина Э.А., Башкатов А.Н., Синичкин Ю.П., Тучин В.В. // Квант. электрон. 2006. Т. 36. № 12. С. 1119; Genina E.A., Bashkatov A.N., Sinichkin Y.P., Tuchin V.V. // Quantum Electronics. 2006. V. 36. N 12. P. 1119. doi 10.1070/QE2006v036n12ABEH013337

[8] Alexandrovskaya Y., Sadovnikov K., Sharov A., Sherstneva A., Evtushenko E., Omelchenko A., Obrezkova M., Tuchin V., Lunin V., Sobol E. // J. Biophotonics. 2018. V. 11. N 2. P. e201700105. doi 10.1002/jbio. 201700105

[9] Alexandrovskaya Y.M., Evtushenko E.G., Obrezkova M.M., Tuchin V.V., Sobol E.N. // J. Biophotonics. 2018. V. 11. N 12. P. e201800195. doi 10.1002/jbio.201800195

[10] Башкатов А.Н., Генина Э.А., Синичкин Ю.П., Кочубей В.И., Лакодина Н.А., Тучин В.В. // Биофизика. 2003. T. 48. C. 309.

[11] Ларин К.В., Тучин В.В. // Квант. электрон. 2008. Т. 38. № 6. C. 551; Larin K.V., Tuchin V.V. // Quantum Electronics. 2008. V. 38. N 6. P. 551. doi 10.1070/QE2008v038n06ABEH013850

[12] Тучина Д.К., Генин В.Д., Башкатов А.Н., Генина Э.А., Тучин В.В. // Опт. и спектр. 2016. Т. 120. № 1. С. 36; Tuchina D.K., Genin V.D., Bashkatov A.N., Genina E.A., Tuchin V.V. // Opt. Spectrosc. 2016. V. 120. N 1. P. 28. doi 10.1134/S0030400X16010215 
[13] Tuchina D.K., Shi R., Bashkatov A.N., Genina E.A., Zhu D., Luo Q., Tuchin V.V. // J. Biophotonics. 2015. V. 8. N 4. P. 332. doi $10.1002 /$ jbio. 201400138

[14] Tearney G.J., Brezinski M.E., Bouma B.E., Hee M.R., Southern J.F., Fujimoto J.G. // Opt. Lett. 1995. V. 20. N 21. P. 2258. doi 10.1364/OL.20.002258

[15] Kim Y.L., Walsh Jr J.T., Goldstick T.K., Glucksberg M.R. // Physics in Medicine \& Biology. 2004. V. 49. N 5. P. 859. doi 10.1088/0031-9155/49/5/015

[16] Sorin W.V., Gray D.F. // IEEE Photon. Technol. Lett. 1992. V. 4. N 1. P. 105. doi $10.1109 / 68.124892$

[17] Wang X.J., Milner T.E., Chang M.C., Nelson J.S.J. // Biomed. Opt. 1996. V. 1. N 2. P. 212. doi 10.1117/12.227699

[18] Shvachkina M.E., Yakovlev D.D., Pravdin A.B., Yakovlev D.A. // J. Biomed. Phot. \& Eng. 2018. V. 4. N 1. P. 010302. doi 10.18287/JBPE18.04.010302

[19] Bor Z., Osvay K., Racz B., Szabo G. // Opt. Commun. 1990. V. 78. N 2. P. 109. doi 10.1016/0030-4018(90)90104-2

[20] Born M., Wolf E. Principles of optics: electromagnetic theory of propagation, interference and diffraction of light. Cambridge University Press, 1999. 987 p.

[21] Segelstein D. // J. The Complex Refractive Index of Water. Doctoral dissertation. Kansas City: University of MissouriKansas City, 1981. 175 p.

[22] De Chaumont F., Dallongeville S., Chenouard N. et al. // Nature Methods. 2012. V. 9. N 7. P. 690. doi $10.1038 /$ nmeth.2075

[23] Morin C., Hellmich C., Henits P. // J. Theoretical Biology. 2013. V. 317. N 21. P. 384. doi 10.1016/j.jtbi.2012.09.026

[24] Leonard D.W., Meek K.M. // Biophysical J. 1997. V. 72. N 3. P. 1382. doi 10.1016/S0006-3495(97)78784-8 